\title{
LA AUTOREPRESENTACIÓN A TRAVÉS DEL FOTO-BORDADO COMO GENERADORA DE DIÁLOGO EN LA ETNOGRAFÍA EXPERIMENTAL
}

SELF-REPRESENTATION THROUGH PHOTO-EMBROIDERY AS A GENERATOR OF DIALOGUE IN EXPERIMENTAL ETHNOGRAPHY

\section{RESUMEN}

Este estudio se centra en analizar si a través de una etnografía experimental de autorepresentación por medio del foto-bordado, se pueden obtener datos relevantes sobre los discursos socioculturales generados. Dado los escasos estudios efectuados bajo este método, su importancia radica en el aporte metodológico y experiencial para la generación de una perspectiva teórica especifica. En el año 2001, un grupo de mujeres tejedoras de la comunidad de Nizag, en el cantón Alausí, provincia de Chimborazo, Ecuador; se organizan en torno a sus tejidos ancestrales y conforman la Corporación de Mujeres Artesanas de Nizag, COMANI, para enfrentar la soledad y el abandono por los altos índices de migración, la escasa producción agrícola y la pobreza. Por medio de talleres, en el contexto de una etnografía experimental de 100 días de duración, se proporcionó a cada participante su retrato impreso en tela, para que a través del bordado se auto representaran y narraran sus inquietudes por medio de hilos, agujas, formas y colores. Los diálogos generados a partir de las lecturas realizadas a sus fotobordados, son lo más importantes en cuanto a interés etnográfico, se evidenciaron en las autorepresentaciones, sus preocupaciones, deseos, emociones y elementos de su cultura.

Palabras clave: Etnografía experimental, foto-bordado, representación, asociación de mujeres.

\section{ABSTRACT}

This study focuses on knowing if, through an experimental ethnography of self-representation through photo-embroidery, relevant data can be obtained about the socio-cultural discourses generated. Given the few ethnographic studies carried out under this method, its importance lies in the methodological and experiential contribution for the generation of a specific theoretical perspective. In 2001, a group of women weavers from the community of Nizag, in Alausi canton, Chimborazo province, Ecuador; They are organized around their ancestral fabrics and make up the Corporación de Mujeres Artesanas de Nizag, COMANI, to face loneliness and abandonment due to high migration rates, scarce agricultural production and poverty. Through an experimental ethnography lasting three months, each participant was given his own portrait printed on canvas, so that through embroidery they self-express themselves and tell us about them and their feelings with threads, needles, shapes and colors. In spite of the inconveniences arising in the development of this ethnographic exercise, self-representations, their concerns, desires, emotions and elements of their culture were evident; data and knowledge necessary for future methodological applications.

Keywords: Experimental ethnography, photo-embroidery, representation, women's association.

$$
\text { Robert D. Orozco }
$$

robertorozco.tra@gmail.com 


\section{INTRODUCCIÓN}

La comunidad de Nizag en las tres últimas décadas, ha sufrido una acelerada erosión de sus tierras, provocando una baja producción agrícola, lo que sumado a la falta de empleo, ha llevado a sus habitantes al abandono de sus tierras y a una acelerada migración iniciada en el año 1999.

Según Jokisch (2001) "ciertos cantones de las zonas de envío de emigrantes de la región sur del país, tenían más del $10 \%$ de su población en el extranjero (...) En algunas comunidades, sólo 60 hombres permanecen por cada 100 mujeres" (citado en Gratton 2005:35).

En 1999, el entonces presidente del Ecuador, Jamil Mahuad, "se concentró en la asistencia a los bancos (...) Además se dispuso el congelamiento de depósitos del público y el feriado bancario, asumiendo el Estado el control del $70 \%$ de la banca privada" (Mancero 2001:129). Este hecho representó para el país un punto de inflexión y crisis social, provocando un incremento de la migración internacional, alcanzando notoriedad desde el año 2000.

Antonio Mendoza, habitante de la comunidad de Nizag, recuerda que desde el año 1999 abandonaban la comunidad cerca de 120 jóvenes cada año (comunicación personal, 8 de abril, 2018). En este contexto, un grupo de mujeres deciden organizarse y mediante el fortalecimiento de las prácticas ancestrales, el trabajo colectivo y solidario, y la consolidación de la unidad comunitaria, obtener algún tipo de ingreso que permita cubrir en algo sus necesidades básicas.

Es así, que el trabajo de tejido con fibra de cabuya, principalmente las shigras, tradicionalmente lo aprenden y realizan las mujeres desde muy pequeñas, por lo que se convierte en la técnica y el producto en torno al cual se organizan para crear la COMANI, acción que las llevó a revalorizar el trabajo de tejido, buscar los elementos característicos en sus diseños, catalogarlos y reinterpretarlos, para consecuentemente convertirse en los elementos que distinguirían a una shigra tejida al interior de la comunidad, de las comercializadas en otras partes del país.

Esta investigación se realizó, para descubrir si la aplicación de una etnografía experimental puede fomentar que las mujeres tejedoras de Nizag se autorepresenten a través del fotobordado y generen discursos socioculturales, por lo que el objetivo fue: emplear el fotobordado como método de autorepresentación, con el cual las mujeres tejedoras de Nizag generen diálogos socioculturales.

La autorepresentación es mirarse a sí mismo, mirar dentro de uno, en los bordes, en las esquinas, en los escondrijos y lados más representativos que tenemos y que nos gustaría que los demás conozcan, entiendan, comprendan y acepten; es una forma de resistir a lo que los demás quieren que seamos, que pensemos, que nos veamos. Representarse es exponerse ante los demás como un ser individual y como integrante de un colectivo, con particularidades propias, pero también culturales, heredadas o creadas en la convivencia, necesidad, comodidad $u$ obligación.

Al respecto, se tuvo en cuenta que al encontrarse la antropología visual en un proceso de construcción, experimentación y validación permanente en la práctica etnográfica, la discusión referente a la representación reside en determinar: “¿Cómo nos representamos la diversidad cultural?, ¿Cómo la representación audiovisual interviene en la formación de identidades colectivas?, ¿Cuál es la función de la antropología en la reproducción o análisis crítico de estereotipos culturales sobre la alteridad?" (Ardévol 1998:1).

Sin embargo, frente a la autorepresentación, la pregunta podría ser: ¿De qué manera podemos autorepresentarnos culturalmente? y frente al ejercicio etnográfico planteado:

¿Puede el análisis de los elementos dibujados, bordados o tejidos, constituirse en documentos etnográficos?

La respuesta a priori, podría ser positiva, pues actualmente se generan nuevos discursos visuales a partir de la producción 
de imágenes, en busca de una autodefinición personal, poniendo en circulación otras miradas que dan cuenta de nuevos modos "de ser y estar en el mundo" (Triquell 2012:160). Sin embargo, los escasos estudios escritos en cuanto a ejercicios de autorepresentación a través de foto-bordado, inclinó a los autores de este artículo a procurar con su realización, obtener antecedentes para aportar a futuras experiencias etnográficas, así como generar una perspectiva teórica concreta, que oriente o guíe posteriores aplicaciones metodológicas.

Al carecer de una metodología específica referencial para este ejercicio etnográfico de autorepresentación a través de foto-bordado, los hallazgos inéditos, análisis y discusiones reflejan probablemente esa falencia, conducidas más por el interés de los autores sobre actividades etnográficas colaborativas, que por las necesidades orgánicas de las protagonistas, evadiendo la recomendación que Mariana Rivera hiciera al respecto: "pienso que la autorepresentación sólo es posible cuando esta iniciativa surge de los mismos individuos, es decir, sin la necesidad de que llegue un personaje del exterior, léase antropólogo, cineasta, ingeniero o arqueólogo, a querer proponer un proyecto" (Rivera 2012:78).

\section{METODOLOGÍA}

El artículo se basa en una investigación cualitativo, experimental y etnográfica, a partir de la experiencia de la antropóloga mexicana Mariana Rivera, quien ha tenido acercamientos con tejedoras en México, Colombia, Bolivia y Ecuador, quien además de ser tejedora e investigadora, ha participado y colaborado con distintos colectivos, proyectos y talleres, cuyo fin ha sido intervenir la imagen propia con un sentido más vivencial y afectivo.

Otro antecedente, es el trabajo realizado por el Grupo Costurero por la Memoria de Sonsón, conformado por mujeres organizadas alrededor de la memoria de los desaparecidos y muertos por el conflicto armado en Colombia. Su exposición Tejer con el hilo de la Memoria: puntadas de dignidad en medio de la guerra, SonsónAntioquia-Colombia 2009-2014, narra las historias de injusticia y violencia que se denuncian y cuentan a través de tejidos textiles personales o colectivos, cuya lectura conmovedora transforma la realidad.

Este tipo de ejercicio etnográfico, permite: observar, participar, detonar y analizar prácticas y diálogos de interacción social sobre la cultura, proporcionándoles voz y representación a las tejedoras, que se considera experimental, porque "Las etnografías siempre han sido en cierto sentido experimentales, y ocasionalmente los etnógrafos han hecho explícita su preocupación por las estrategias de escritura" (Marcus \& Fischer 2000:74), pues en la búsqueda constante de un nuevo paradigma en la escritura etnográfica, se descubren ideas, discursos, conocimientos y estrategias para el análisis de datos escritos, narrados o visuales, en las nuevas situaciones de investigación.

En cuanto al diálogo que puede producirse en torno al foto-bordado, hace falta quien realice una lectura de su contenido, una interpretación y decodificación de símbolos, signos, colores y formas; esta lectura y exposición de su autorepresentación, es lo que denominamos discursos socioculturales, pues "El discurso es socialmente constitutivo así como está socialmente constituido; conforma situaciones, objetos de conocimiento, identidades sociales y relaciones interpersonales" (Martínez 2013:6), por tanto, ayuda a comprender a los demás, su entorno social, cultural, político y económico.

El término representación utilizado en el contexto del taller de fotobordado, se diferencia del empleado para el análisis del modo de representación en el cine etnográfico y documental, más unido al lenguaje audiovisual, que al método con el cual las mujeres tejedoras de Nizag utilizan el bordado para incluir elementos 
que las identifiquen cultural y socialmente, y elaborar el discurso visual con el cual se muestran hacia los demás.

Este ejercicio etnográfico experimental, también podría denominarse, tomando el término de la representación audiovisual, como un ejercicio etnográfico colaborativo de representación, cuyo desarrollo también podría llamarse de autorepresentación, en donde las ideas y perspectivas de los otros, los convierten en co-realizadores del ejercicio (Zirión Pérez 2015).

Tomando en cuenta lo experimental del ejercicio de autorepresentación a través del fotobordado, el método utilizado se sustenta de la observación científica. Así mismo, dentro de las técnicas de investigación, se parte de un trabajo de campo cuya duración fue de 100 días, en el que se utilizaron entrevistas no estructuradas considerando el universo pequeño, nuestra experiencia en su manejo, la confianza y rapport alcanzados.

La observación directa utilizada fue individual, de carácter participante no estructurada, donde el investigador se integra como un miembro más del grupo de estudio y participa en actividades, diálogos y preparación de alimentos, lo que permitió obtener información directa contrastando lo que se dice que se hace, con lo que realmente se hace.

Esta investigación etnográfica fue ejecutada en la comunidad indígena de Nizag, perteneciente al cantón Alausí, en la provincia de Chimborazo, Ecuador, con la participación de las tejedoras de la COMANI, grupo fundado en 2001 por 31 socias, que regularmente se reúnen los viernes en su taller artesanal a tejer, principalmente shigras elaboradas con la fibra de cabuya.

Debido a la carga de actividades que tienen las mujeres de la comunidad, ya sea en agricultura, tejido, cuidado de animales, actividades comunitarias y religiosas, así como de alimentación y familiares, se advirtió que llevar el ejercicio etnográfico por medio de talleres no era algo que pudiera aplicarse con ellas; por lo tanto, se realizó una reunión con las participantes donde se socializaron trabajos efectuados por otras mujeres y la técnica a emplearse; además se acordó que los trabajos los terminen en sus casas, y se planificó dos reuniones en el lapso de tres meses, para ver el avance de sus bordados; el proyecto terminó con una exposición en la misma comunidad a finales del mes de agosto de 2018.

La selección de las participantes para la aplicación de esta etnografía no estuvo sujeta a fórmulas de muestreo, sino a la situación real observada en la comunidad en cuanto a la participación de las mujeres asociativamente. Al plantearse el trabajo con las integrantes de COMANI, se constató que de las 31 mujeres miembros, apenas 12 son constantes y activas en la organización, por lo que luego de hacer un recorrido por la comunidad y hablar con algunas mujeres sobre el proyecto y motivarlas a participar, se pudo incrementar a 23 el número de colaboradoras, todas ellas con familiares emigrados y con conocimientos en tejido y bordado. La mitad de las mujeres participantes son analfabetas y varían sus edades entre los 12 y 70 años.

Luego de un primer diálogo con las tejedoras de la COMANI y una exposición a manera de ejemplo por parte de una tallerista, quien colaboró con su propia autorepresentación de foto-bordado, se mostró la técnica y se despejaron dudas sobre la manera de trabajar. El proceso de recolección de datos se realizó en tres momentos en el transcurso de tres meses.

El primer momento fue cuando se determinó la hora, el lugar y la situación en que deseaban ser fotografiadas. El segundo, pasado cinco semanas de la entrega de retratos impresos en tela; tuvimos un primer diálogo y visualización de algunos trabajos terminados, aunque muchas tejedoras aún no comenzaban. El tercer momento fue cinco semanas después para hacer un análisis de sus bordados, escuchar sus comentarios y planificar una exposición de los trabajos en la comunidad. En la tabla 1 se resume esta información. 
Tabla 1: Momentos en la investigación.

\begin{tabular}{|c|c|c|c|c|c|c|}
\hline MOMENTO & ACCIÓN & LUGAR & $\mathbf{N}$. & $\begin{array}{l}\text { INFORMACIÓN } \\
\text { OBTENIDA }\end{array}$ & $\begin{array}{c}\text { AVANCE } \\
\text { BORDADO }\end{array}$ & $\begin{array}{l}\text { INSTRUMENTOS } \\
\text { RECOLECCIÓN DE } \\
\text { DATOS }\end{array}$ \\
\hline PRIMERO & $\begin{array}{l}\text { Fotografiar a } \\
\text { participantes. }\end{array}$ & $\begin{array}{l}\text { Comunidad } \\
\text { de Nizag }\end{array}$ & 23 & $\begin{array}{l}\text { Retratos de todas las } \\
\text { participantes en fechas, } \\
\text { situación y lugares acordados. }\end{array}$ & $\begin{array}{l}\text { Ninguno por } \\
\text { tratarse del } \\
\text { primer momento. }\end{array}$ & $\begin{array}{l}\text { Observación, } \\
\text { entrevistas no } \\
\text { estructuradas, } \\
\text { filmación, fotografía, } \\
\text { grabación. }\end{array}$ \\
\hline SEGUNDO & $\begin{array}{l}\text { Avance de los } \\
\text { bordados. }\end{array}$ & $\begin{array}{l}\text { Taller de } \\
\text { COMANI }\end{array}$ & 7 & $\begin{array}{l}\text { Técnicas de bordado, } \\
\text { elementos de interés, } \\
\text { preocupaciones varias, dudas } \\
\text { técnicas. }\end{array}$ & $\begin{array}{l}2 \text { ya terminaron, } \\
3 \text { ya iniciaron, } \\
2 \text { aún no } \\
\text { comienzan. }\end{array}$ & $\begin{array}{l}\text { Observación, } \\
\text { entrevistas no } \\
\text { estructuradas, } \\
\text { filmación, fotografía, } \\
\text { grabación. }\end{array}$ \\
\hline TERCERO & $\begin{array}{l}\text { Exposición } \\
\text { personal de } \\
\text { fotobordados. }\end{array}$ & $\begin{array}{l}\text { COMANI y } \\
\text { alrededores }\end{array}$ & 10 & $\begin{array}{l}\text { Experiencias, anécdotas, } \\
\text { sentimientos, dificultades } \\
\text { y satisfacciones con el } \\
\text { ejercicio. Comentarios sobre } \\
\text { los elementos bordados, } \\
\text { sus familias, artesanías, } \\
\text { situaciones personales de } \\
\text { migración, económicas, } \\
\text { organizativas y comunitarias. }\end{array}$ & $\begin{array}{l}\text { De las } 10 \\
\text { asistentes, } 9 \text { ya } \\
\text { terminaron y } 1 \\
\text { lo terminó en ese } \\
\text { momento. }\end{array}$ & $\begin{array}{l}\text { Observación, } \\
\text { entrevistas no } \\
\text { estructuradas, } \\
\text { filmación, fotografía, } \\
\text { grabación. }\end{array}$ \\
\hline EXPOSICIÓN & $\begin{array}{l}\text { Exposición } \\
\text { general de } \\
\text { fotobordados. }\end{array}$ & $\begin{array}{l}\text { Casa } \\
\text { comunal de } \\
\text { Nizag, sede } \\
\text { Gobierno } \\
\text { comunitario }\end{array}$ & 16 & $\begin{array}{l}\text { Apreciación de invitados } \\
\text { especiales, comentarios de } \\
\text { autoridades y habitantes de } \\
\text { la comunidad; reacción de } \\
\text { asistentes. }\end{array}$ & Terminados. & $\begin{array}{l}\text { Observación, } \\
\text { entrevistas no } \\
\text { estructuradas, } \\
\text { filmación, fotografía, } \\
\text { grabación. }\end{array}$ \\
\hline
\end{tabular}

Fuente: Elaboración propia, en base al proceso de investigación.

El proceso se documentó en video y parcialmente en fotografía, aunque no se pudo ubicar a cada una de las mujeres en el transcurso del ejercicio, pues algunas participantes trabajaron en sus casas en su tiempo libre y muchas no acudieron a las fechas acordadas para los diálogos.

Para la implementación del ejercicio, fue necesario contar con retratos de cada una de las participantes, por lo que luego del diálogo mantenido con la mayoría de ellas, y ante la dificultad de obtener imágenes de archivos personales, pues no todas contaban con fotografías con las que deseaban trabajar sus bordados, se decidió por consenso fotografiarlas y procesar esas imágenes para su posterior impresión sobre tela, a través de la técnica de estampado textil (sublimación) y ser entregadas a cada una para iniciar el bordado.

Fue utilizada una cámara fotográfica profesional Canon 7D Mark II, y las participantes escogieron día, lugar y cómo deseaban ser fotografiadas. Posteriormente se utilizó una computadora y el programa de edición de imágenes Photoshop Pro, para dimensionar las fotografías en tamaño y resolución, para su impresión y revelado en telas sintéticas de 45 x $38 \mathrm{~cm}$ y un área de impresión de 27 x $36 \mathrm{~cm}$.

Las imágenes fueron impresas a color, con tintas de sublimación, que fueron pasadas a las telas a través de una estampadora o plancha de calor de formato medio. Las telas listas fueron entregadas a las participantes, junto a un tambor de bordado, un juego de hilos y agujas; sin embargo, se les alentó a utilizar cualquier tipo de material que desearan en sus bordados.

Para el ejercicio de autorepresentación, las participantes debían considerar cualquier elemento con el que se identificasen o les guste, así como reflejar sus sentimientos, sus deseos o temores; también podrían intentar contarnos algo de su vida, de la comunidad o de sus familiares, pues la intención principal era que puedan bordar historias, ideas, necesidades. 


\section{RESULTADOS Y DISCUSIÓN}

Como resultados relevantes del proceso de investigación etnográfica, los distintos momentos aportaron datos que son analizados a partir de esos tres instantes. En el primer momento, al retratar a las participantes en el lugar, el día y en la situación que ellas habían escogido, nueve mujeres de las 23 retratadas prefirieron la misma sede donde se reúnen a tejer sus artesanías, ya sea trabajando en algún aspecto del proceso del tejido o posando con algún implemento de la actividad. Ocho prefirieron ser retratadas en sus casas, bien en sus jardines, dando de comer a los animales o junto a algún familiar; tres prefirieron un retrato con la cabuya, cortándola y limpiándola; y tres con su shigra, tanto tejiéndola como posando con ella (tabla 2).

De estos datos se despende que el primer gesto de autorepresentarse se inició en el momento en que decidieron el lugar y el cómo querían ser retratadas; las participantes que escogieron el taller artesanal de la corporación, lo hicieron principalmente por comodidad al no tener que buscar otro día para realizar la fotografía; también para no tener que invitarnos a su casa, pues a pesar de que todas pertenecen a la misma comunidad, algunas se sienten menos afortunadas que otras y avergonzadas de las condiciones en las que viven. Sin embargo, la mayoría que escogió este lugar se sentían más cómodas por la presencia de sus compañeras y porque estaban habituadas a que ocasionalmente se hallen cámaras registrando sus actividades de tejido.

Cuando nos reunimos en el taller artesanal para realizar los retratos, la mayoría se encontraba hilando las fibras de cabuya para sus shigras, por lo que cinco de ellas decidió que se las retrate realizando esa actividad. Esta parte del proceso artesanal no es muy agradable para la mayoría y querían mostrarse fuertes, luchadoras y orgullosas de su trabajo; mientras que las restantes escogieron el telar, tejer o algún material de

Tabla 2: Primer momento en la investigación.

\begin{tabular}{|c|c|c|c|c|}
\hline \multicolumn{5}{|c|}{ PRIMER MOMENTO (retratar a participantes) } \\
\hline & TALLER DE COMANI & $\begin{array}{l}\text { LUGAR DE } \\
\text { RESIDENCIA }\end{array}$ & PLANTA DE CABUYA & CON SHIGRA \\
\hline $\begin{array}{l}\text { NÚMERO DE } \\
\text { PARTICIPANTES }\end{array}$ & 9 & 8 & 3 & 3 \\
\hline SITUACION & $\begin{array}{l}\text { Tejiendo, hilando, con } \\
\text { herramientas de actividad } \\
\text { de tejido, en telar. }\end{array}$ & $\begin{array}{l}\text { En Jardines, huertos, con } \\
\text { animales, junto a familiares, }\end{array}$ & $\begin{array}{l}\text { Cortando hojas de } \\
\text { cabuya, quitando espinas, } \\
\text { limpiándola. }\end{array}$ & $\begin{array}{l}\text { Tejiendo shigra, posando } \\
\text { con ella. }\end{array}$ \\
\hline $\begin{array}{l}\text { GESTO DE } \\
\text { AUTOREPRESEN- } \\
\text { TACIÓN }\end{array}$ & $\begin{array}{l}\text { Deseo de querer } \\
\text { mostrarse como artesanas, } \\
\text { pertenecer a COMANI, } \\
\text { saber hilar, saber tejer. }\end{array}$ & $\begin{array}{l}\text { Orgullosas de sus jardines } \\
\text { o huertos, autosuficientes, } \\
\text { tienen y cuidan sus } \\
\text { animales, importancia de la } \\
\text { familia, soledad y lucha. }\end{array}$ & $\begin{array}{l}\text { Fuertes y diestras en el } \\
\text { manejo de herramientas } \\
\text { y de la planta, autoestima } \\
\text { alta. }\end{array}$ & $\begin{array}{l}\text { Saber tejer shigra, saber } \\
\text { dar forma a la fibra de } \\
\text { cabuya, saber diseñar y } \\
\text { hacer objetos hermosos. }\end{array}$ \\
\hline OBSERVACIONES & $\begin{array}{l}\text { La mayoría se sentía } \\
\text { cómoda al ser retratada } \\
\text { en el taller artesanal, } \\
\text { por hallarse junto a sus } \\
\text { compañeras. Algunas } \\
\text { tienen vergüenza } \\
\text { invitarme a su casa. }\end{array}$ & $\begin{array}{l}\text { Tía Rosario se quitó el } \\
\text { sombrero. fueron sesiones } \\
\text { fotográficas más largas, } \\
\text { pues posaron con muchos } \\
\text { familiares. Se quiso } \\
\text { evidenciar algún tipo de } \\
\text { compromiso adquirido. } \\
\text { Imágenes más íntimas y } \\
\text { personales. }\end{array}$ & $\begin{array}{l}\text { Las participantes estaban } \\
\text { muy animadas, alegres y } \\
\text { deseosas de ser retratadas } \\
\text { cosechando cabuya; hubo } \\
\text { llovizna. }\end{array}$ & $\begin{array}{l}\text { Katalina no quiso un } \\
\text { nuevo retrato, pidió se } \\
\text { use una imagen obtenida } \\
\text { anteriormente. Las dos } \\
\text { restantes fueron retratos } \\
\text { completamente posados. }\end{array}$ \\
\hline
\end{tabular}

Fuente: Elaboración propia, en base al proceso de investigación. 
trabajo.

Debemos tener en cuenta que las imágenes obtenidas no fueron autorretratos de las participantes sino una representación, si bien no $100 \%$ definida por el fotógrafo, si afectada por la mirada, la cámara, la estética y el conocimiento por parte del autor de cada una de ellas. Estos retratos procuraron ser honestos y coherentes con sus requerimientos personales; aunque a veces idealizados, respondieron satisfactoriamente a sus deseos, no obstante, un ejercicio con verdaderos autorretratos habría sido más interesante por el valor de la mirada, la autoestima y la autovaloración de sí mismo, ya que según Albert Collette, el self es considerado como "la imagen que una persona tiene de su yo" (1969:95). Esta consideración habría hecho del ejercicio de autorepresentación a través del foto-bordado, una experiencia más integral.

De las ocho mujeres que eligieron su casa para ser retratadas, siete escogieron sus jardines o huertos para el retrato; se sentían contentas de estar en sus casas, de manera especial la tía Rosario, quien definitivamente sabía que quería retratarse dando de comer a sus animales, misma que al momento de ser fotografiada se quitó el sombrero para ser mejor reconocida.

Lo importante aquí es la relación directa de las mujeres con sus huertos y jardines, y su orgullo por mantenerlos bien cuidados y produciendo lo que diariamente consumen. La comunidad de Nizag posee tres pisos climáticos denominados según Salomon (1980) pisos verticales y ecológicos, pues la Hoya del Chanchan, zona en la que se ubica la comunidad, "se caracteriza por tener una enorme riqueza y diversidad natural y productiva que los pueblos han aprovechado a lo largo de la historia" (Auqui 2016:52).

El que algunas mujeres prefirieran retratarse junto a un familiar está sujeto a asuntos emocionales y eventualmente evidenciar algún tipo de compromiso adquirido. Nelly Mendoza deseó ser retratada con sus dos hijos, pues al parecer ya tenía en mente lo que haría con su retrato. Este fue uno de los trabajos que nunca pude documentar, pues su autora lo había enviado a su esposo que se encuentra en el extranjero; decisión igual fue tomada por su hija Mercy y su tía Rosario Mendoza.

Por su parte Dolores Vacacela quien actualmente es la presidenta de la COMANI, pidió ser retratada junto a su sobrino Wilmer, de quien se hizo cargo desde hace 9 años atrás, por la migración de su hermano. El muchacho llama mamá a su tía aunque sabe muy bien quiénes son sus padres. Dolores no tiene hijos propios, pero ha cuidado de él desde el primer día como si lo fuera, por lo que se entiende que en su retrato procure perennizar sus afectos hacia Wilmer.

Margarita Mendoza deseó ser retratada junto a su pequeño nieto Kevin, al que se sumó un travieso cabrito que le dio un toque de espontaneidad y alegría al retrato; habíamos sido invitados estar muy temprano en su casa, pues luego de las siete de la mañana se iría al campo.

De este grupo de mujeres que escogieron su vivienda como lugar para ser retratadas, todas tienen a su esposo, padre, sobrino, hermano e hijo en el extranjero, pues el tema de la migración es una constante en la comunidad, así como en la redacción y documentación etnográfica.

Según el censo poblacional del 2001, la población inmigrante indígena de Chimborazo hacia las provincias del Guayas y Pichincha era del 34,7 \%, la más alta a nivel nacional (INEC 2002); y en el 2010, el cantón Alausí ocupó el primer lugar en migración, con un total de 530 migrantes, de los cuales 328 eran hombres, esto además de reflejar un recrudecimiento de la pobreza que llegaba al $66,5 \%$ en el cantón por necesidades básicas insatisfechas (INEC 2010).

Esta situación provocó un desmembramiento familiar con profundas consecuencias sociales, políticas, económicas y culturales para los habitantes de Nizag; muchos niños fueron criados por un pariente o amigo de la familia, sufren en soledad las consecuencias del abandono, por lo que los matrimonios a muy tempranas edades son bastante 


\section{comunes.}

María Presentación, María Dolores y María Teresa decidieron ser retratadas con las hojas de cabuya; Presentación las cortó y Dolores con Teresa las limpiaron de espinas. Nos encontrábamos en el taller artesanal cuando simplemente dijeron que querían en ese momento que se las retrate sacando las hojas de cabuya; tomaron sus implementos y bajo una llovizna salieron hacia los linderos donde se encontraban sembradas algunas plantas; estaban muy contentas de ser retratadas en esa actividad, pues como diría M.P. Vacacela "debemos tener una autoestima alta por lo que hacemos" (comunicación personal, 30 de junio, 2018).

Este argumento de Presentación ya lo habíamos escuchado en otros espacios y diálogos previos, así como posteriores, pues el formar parte de las mujeres artesanas de Nizag, no sólo es un tema relacionado con lo económico, sino que además, son respetadas por sus conocimientos y empeño por preservar los saberes heredados de sus mayores, trabajo que muchas mujeres, sobre todo las más jóvenes, preocupantemente ya no realizan.

Los últimos tres retratos corresponden a quienes aparecen con sus shigras ya sea tejiéndola o posando con ella. Katalina Tapay Mendoza actualmente dirigente de la COMANI, solicitó se utilice una imagen obtenida meses antes en un recorrido hacia la estación del tren de Sibambe, mejor conocida como la Nariz del Diablo; ella se identificó mucho con esa imagen que la prefirió para su trabajo de bordado. Por otro lado, las dos restantes posaron con su shigra en proceso. En la figura 1 se pueden apreciar algunos de los retratos descritos.

En el segundo momento de recolección de datos, se dialogó con algunas mujeres sobre el avance de sus bordados, dos de laspresentes prácticamente ya habían terminado y otras aún no lo habían iniciado. En el diálogo, quienes habían avanzado en el proceso de bordado, mostraron interés en compartir las técnicas que estaban aplicando, mientras que otras intentaban explicar el por qué de algunos elementos en sus diseños (tabla 3 ).

Fuente: Elaboración propia.

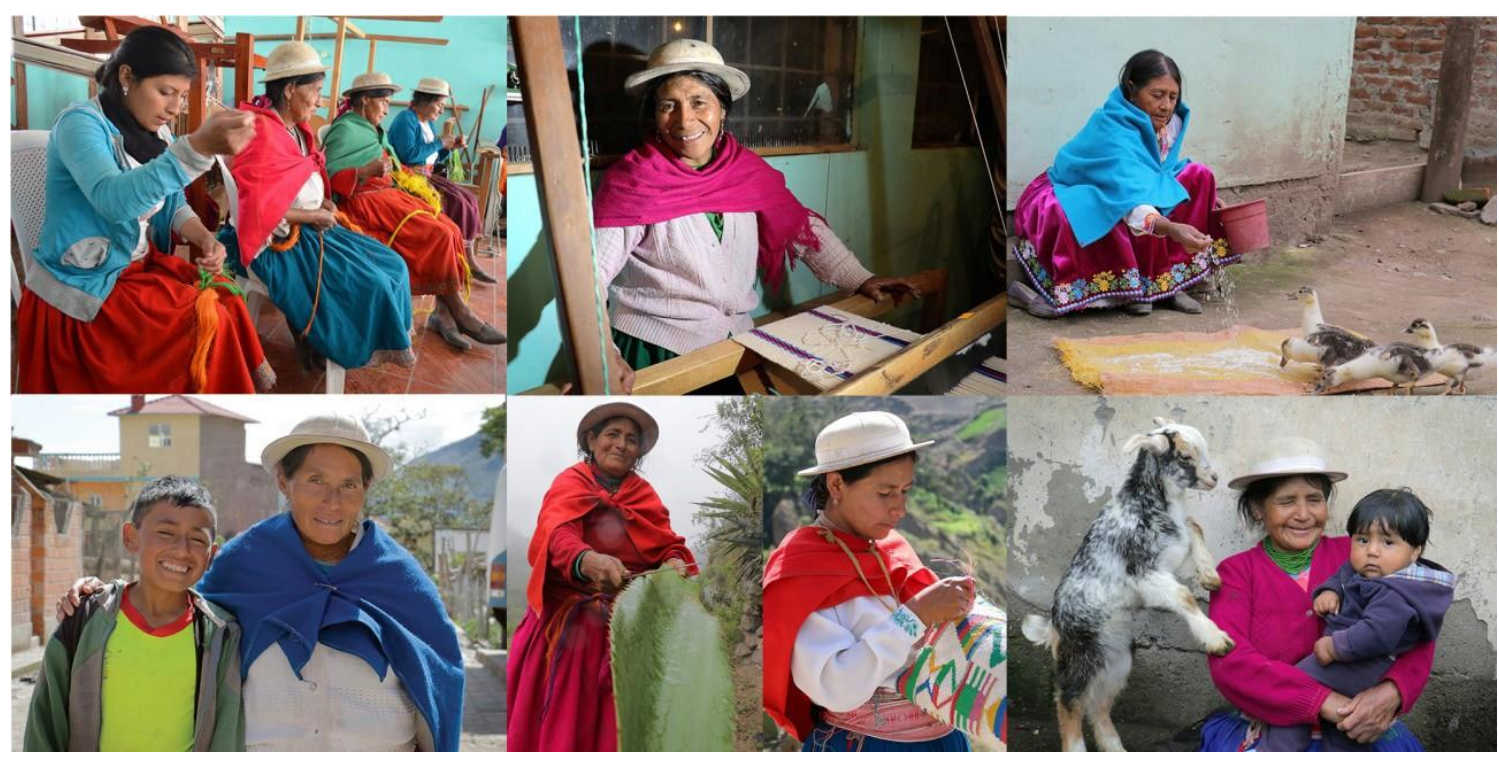

Figura 1: Retratos varios para trabajo de foto-bordado 
Tabla 3: Segundo momento en la investigación.

\begin{tabular}{|c|c|c|c|}
\hline \multicolumn{4}{|c|}{ SEGUNDO MOMENTO (avances de foto-bordado) } \\
\hline $\begin{array}{c}\text { NÚMERO DE } \\
\text { PARTICIPANTES: } 7\end{array}$ & TERMINARON & INICIARON & NO INICIAN \\
\hline NIVEL DE TRABAJO & 2 & 3 & 2 \\
\hline TÉCNICAS & $\begin{array}{l}\text { Punto atrás, encadenado, escapulario, } \\
\text { punto corrido, punto relleno. }\end{array}$ & $\begin{array}{l}\text { Punto atrás, encadenado, } \\
\text { escapulario, punto relleno. }\end{array}$ & No se menciona. \\
\hline $\begin{array}{l}\text { ELEMENTOS A } \\
\text { DISEÑARSE }\end{array}$ & Flores, hojas, pétalos, letras, palabras, & $\begin{array}{l}\text { Flores, hojas, pétalos, letras, } \\
\text { palabras, animales, sol, luna, } \\
\text { corazón, elementos decorativos. }\end{array}$ & $\begin{array}{l}\text { Flores, hojas, pétalos, letras, } \\
\text { palabras, animales, sol, luna, } \\
\text { montañas, casas, elementos } \\
\text { decorativos. }\end{array}$ \\
\hline $\begin{array}{l}\text { GESTO DE AUTO } \\
\text { REPRESENTACIÓN }\end{array}$ & $\begin{array}{l}\text { Que sus hijos sepan que su madre es } \\
\text { artesana. Que extrañan a sus hijos. Que } \\
\text { saben procesar la fibra de cabuya. }\end{array}$ & $\begin{array}{l}\text { Que pertenecen a Nizag, } \\
\text { cosmovisión andina, que son } \\
\text { indígenas. No me gusta la migración. } \\
\text { Me encantan las flores. }\end{array}$ & No aplica. \\
\hline OBSERVACIONES & $\begin{array}{l}\text { Las mujeres enseñaban las técnicas } \\
\text { de bordado utilizadas en sus trabajos. } \\
\text { Interacción con mujeres ajenas a la } \\
\text { COMANI, }\end{array}$ & $\begin{array}{l}\text { Dos mujeres pidieron que les tome } \\
\text { e imprima una nueva foto, pues no } \\
\text { estaban satisfechas con las recibidas. }\end{array}$ & $\begin{array}{l}\text { Se mostraron interesadas en } \\
\text { contar lo que harían en sus } \\
\text { telas y preguntar sobre cómo } \\
\text { hacerlo. }\end{array}$ \\
\hline
\end{tabular}

Fuente: Elaboración propia, en base al proceso de investigación.

A este segundo momento del ejercicio de autorepresentación, sólo llegaron siete mujeres con sus bordados, es decir el 30\% de las participantes. En este diálogo resalto el interés de las mujeres de compartir su técnica con las demás, creándose un espacio de interacción con mujeres tejedoras que no pertenecen a la COMANI, situación que nos lleva a valorar las relaciones que se generan en torno al bordado y el tejido, permitiéndoles entablar nuevas sociedades de trabajo y colaboración, pues algunas mujeres volverían posteriormente con shigras para entregar a la COMANI para su comercialización.

En este punto del proceso, y aunque se habían previsto todas las posibles complicaciones que en el desarrollo del ejercicio podrían surgir, y luego de haber facilitado la manera de realizar el trabajo sin presión o demasiado control, metodológicamente si bien estaba pensado acorde a la realidad de las mujeres tejedoras de Nizag, podría mejorar y darnos resultados etnográficos más inmediatos y significativos, si se lo realizara a través de talleres con encuentros permanentes de interrelación, intercambio y diálogo.
En el tercer momento, los datos tienen que ver con la exposición personal de sus fotobordados. En este punto, las participantes compartieron su experiencia, lo realizado, los elementos utilizados, las dificultades presentadas y algunas utilizaron el espacio para agradecer, hablar de sus familiares, de sus artesanías, situaciones personales, organizativas y comunitarias. Ante la dificultad de la mayoría para expresarse adecuadamente en español, se les sugirió que hablaran en su lengua originaria; sin embargo, solo dos de ellas hablaron en kichwa (tabla 4). 
Tabla 4: Tercer momento en la investigación.

\section{TERCER MOMENTO (exposición personal de fotobordados)}

\begin{tabular}{|c|c|c|c|c|c|}
\hline $\begin{array}{c}\text { NÚMERO DE } \\
\text { PARTICIPANTES: } \\
10\end{array}$ & $\begin{array}{l}\text { TIPO DE } \\
\text { INTERVEN- } \\
\text { CIÓN / } \\
\text { TÉCNICA DE } \\
\text { BORDADO } \\
\end{array}$ & $\begin{array}{c}\text { ELEMENTOS, } \\
\text { DISEÑOS, } \\
\text { SÍMBOLOS }\end{array}$ & DISCURSO PRINCIPAL & $\begin{array}{c}\text { DISCURSO } \\
\text { SECUNDARIO }\end{array}$ & $\begin{array}{l}\text { AUTOREPRE- } \\
\text { SENTACIÓN }\end{array}$ \\
\hline $\begin{array}{l}\text { MARÍA TERESA } \\
\text { PALA }\end{array}$ & $\begin{array}{l}\text { Exterior e } \\
\text { interior / } \\
\text { Escapulario, } \\
\text { zigzag, } \\
\text { punto atrás, } \\
\text { encadenado, } \\
\text { punto corrido, } \\
\text { punto relleno. }\end{array}$ & $\begin{array}{c}\text { Flores, pétalos, } \\
\text { hojas, formas } \\
\text { decorativas. }\end{array}$ & $\begin{array}{l}\text { Para mi, este bordado } \\
\text { es un recuerdo, para que } \\
\text { sepan que he trabajado } \\
\text { en artesanía. Esta florcita } \\
\text { es para mis hijos como } \\
\text { recuerdo por el día de } \\
\text { la madre. Es mi foto, } \\
\text { y cuando muera van a } \\
\text { enviar en cajita. }\end{array}$ & $\begin{array}{l}\text { Distintos productos que } \\
\text { elaboran en la COMANI. } \\
\text { Yo recojo cabuya negra y } \\
\text { blanca para hacer shigra. } \\
\text { Antes solo sembrábamos } \\
\text { y cuidábamos animalitos, } \\
\text { ahora aprendimos hacer } \\
\text { artesanía, recibimos } \\
\text { algunos centavitos para } \\
\text { comprar al menos sal. }\end{array}$ & $\begin{array}{l}\text { Orgullosa mujer } \\
\text { artesana de Nizag } \\
\text { que conoce muy } \\
\text { bien su oficio. } \\
\text { Madre que ama a } \\
\text { sus hijos. }\end{array}$ \\
\hline $\begin{array}{l}\text { MARÍA } \\
\text { PRESENTACIÓN } \\
\text { VACACELA }\end{array}$ & $\begin{array}{l}\text { Interior / } \\
\text { Punto atrás, } \\
\text { encadenado, } \\
\text { punto relleno, } \\
\text { punto de } \\
\text { contorno. }\end{array}$ & $\begin{array}{l}\text { Hojas, } \\
\text { intervención } \\
\text { sobre la imagen. }\end{array}$ & $\begin{array}{l}\text { Estoy cosechando cabuya } \\
\text { negra para obtener la } \\
\text { fibra. Quiero poner en un } \\
\text { marco para ver yo misma } \\
\text { y que mis hijos sepan que } \\
\text { he sido artesana. Debemos } \\
\text { tener autoestima. }\end{array}$ & $\begin{array}{l}\text { Pertenezco a la } \\
\text { COMANI. Yo dibujé las } \\
\text { plantas y espinos de la } \\
\text { foto, también las hojas } \\
\text { cortadas. Yo quiero } \\
\text { mucho este trabajo con } \\
\text { la fibra. }\end{array}$ & $\begin{array}{l}\text { Soy artesana de la } \\
\text { fibra de cabuya. } \\
\text { Que todos sepan } \\
\text { que ella es indígena } \\
\text { y artesana. }\end{array}$ \\
\hline $\begin{array}{l}\text { MARÍA NATIVIDAD } \\
\text { TENEMAZA }\end{array}$ & $\begin{array}{l}\text { Interior y } \\
\text { exterior / } \\
\text { Punto atrás, } \\
\text { encadenado, } \\
\text { punto relleno, } \\
\text { punto de } \\
\text { contorno, } \\
\text { punto hoja. }\end{array}$ & $\begin{array}{l}\text { Flores, estrella, } \\
\text { casa, barco, pato, } \\
\text { nombre. }\end{array}$ & $\begin{array}{l}\text { Mi hija se fue a Estados } \\
\text { Unidos por mar. Mi casita } \\
\text { no se termina de construir. } \\
\text { Quiero que siempre me } \\
\text { recuerden como artesana } \\
\text { por eso he puesto mi } \\
\text { nombre. }\end{array}$ & $\begin{array}{l}\text { Para vivir tejemos } \\
\text { artesanía. Tengo lindas } \\
\text { flores en mi casa. Tengo } \\
\text { animalitos por eso he } \\
\text { puesto un pato. }\end{array}$ & $\begin{array}{l}\text { La migración es } \\
\text { tema de mucha } \\
\text { preocupación, al } \\
\text { igual que su familia } \\
\text { y la artesanía. }\end{array}$ \\
\hline MÓNICA MENDOZA & $\begin{array}{l}\text { Interior y } \\
\text { exterior / } \\
\text { Punto atrás, } \\
\text { encadenado, } \\
\text { punto relleno, } \\
\text { punto de } \\
\text { contorno, } \\
\text { punto hoja, } \\
\text { flor brasileña, } \\
\text { nudo francés, } \\
\text { punto red. }\end{array}$ & $\begin{array}{l}\text { Flores de distinta } \\
\text { forma y tamaño, } \\
\text { montañas, } \\
\text { hojas, tallos, } \\
\text { árbol, nombre, } \\
\text { intervención } \\
\text { sobre la imagen. }\end{array}$ & $\begin{array}{l}\text { Las distintas flores son } \\
\text { mis familiares que viven } \\
\text { aquí o en otro país, en } \\
\text { especial mi esposo que } \\
\text { está muy lejos y yo lo } \\
\text { extraño mucho. También } \\
\text { representan mis hijos } \\
\text { cuyos nombres también } \\
\text { están bordados. El anaco } \\
\text { es una prenda de vestir } \\
\text { que antiguamente se } \\
\text { ponían las mujeres por eso } \\
\text { le borde uno a mi mamá } \\
\text { en la foto. }\end{array}$ & $\begin{array}{l}\text { En mi casa tenemos } \\
\text { un árbol antiguo que } \\
\text { nunca lo tumbaremos. } \\
\text { La familia es importante } \\
\text { por eso bordé un ramo } \\
\text { de flores de todos los } \\
\text { colores. }\end{array}$ & $\begin{array}{l}\text { Desea que } \\
\text { sus familiares } \\
\text { migrantes vuelvan } \\
\text { pues los extraña } \\
\text { mucho. Importante } \\
\text { recalcar que su } \\
\text { comunidad se } \\
\text { encuentra entre } \\
\text { las montañas. } \\
\text { Preocupada de } \\
\text { su cultura y su } \\
\text { preservación. }\end{array}$ \\
\hline $\begin{array}{l}\text { MARÍA KATALINA } \\
\text { TAPAY }\end{array}$ & $\begin{array}{l}\text { Exterior / } \\
\text { Escapulario, } \\
\text { zigzag, punto } \\
\text { atrás, punto } \\
\text { relleno. }\end{array}$ & $\begin{array}{l}\text { Puntadas } \\
\text { decorativas, } \\
\text { ninguna forma. }\end{array}$ & $\begin{array}{l}\text { Yo debo quedar libre en } \\
\text { mi fotografía por eso } \\
\text { solo diseñé fuera de mi } \\
\text { imagen. No me gusta que } \\
\text { mi esposo me diga lo que } \\
\text { debo hacer. Es importante } \\
\text { que la COMANI no se } \\
\text { termine. }\end{array}$ & $\begin{array}{l}\text { Me arrepiento no haber } \\
\text { cogido flores para teñir } \\
\text { las shigras. } \\
\text { Los colores que uso en } \\
\text { mis diseños también son } \\
\text { los de mi vestimenta y } \\
\text { se encuentran en nuestra } \\
\text { naturaleza. }\end{array}$ & $\begin{array}{l}\text { Mujer } \\
\text { independiente, con } \\
\text { mucho deseo de } \\
\text { cambiar a través } \\
\text { de la educación su } \\
\text { futuro y situación } \\
\text { familiar. Le gusta } \\
\text { su cultura, la } \\
\text { investiga y difunde. }\end{array}$ \\
\hline $\begin{array}{l}\text { OTRAS } \\
\text { PARTICIPANTES }\end{array}$ & $\begin{array}{l}\text { Mixta / Punto } \\
\text { atrás, punto } \\
\text { relleno, } \\
\text { encadenado, } \\
\text { punto de } \\
\text { contorno, } \\
\text { punto hoja, } \\
\text { nudo francés, } \\
\text { punto red, } \\
\text { escapulario, } \\
\text { zigzag. }\end{array}$ & $\begin{array}{l}\text { Puntadas } \\
\text { decorativas, } \\
\text { distintos } \\
\text { animales, sol, } \\
\text { luna, flores de } \\
\text { muchas formas } \\
\text { y colores, } \\
\text { hojas, estrellas, } \\
\text { nombres propios } \\
\text { y de lugares, } \\
\text { iniciales, }\end{array}$ & $\begin{array}{l}\text { Somos mujeres artesanas } \\
\text { indígenas, nuestra } \\
\text { comunidad está llena de } \\
\text { naturaleza, todas tenemos } \\
\text { familiares en el extranjero. } \\
\text { Nuestra artesanía nos } \\
\text { permite ayudar en } \\
\text { nuestros hogares. }\end{array}$ & $\begin{array}{l}\text { Elaboramos muchas } \\
\text { cosas en artesanía. Nos } \\
\text { gusta tener florcitas, } \\
\text { animales, huertos con } \\
\text { frutales. Nuestro trabajo } \\
\text { es duro. Una shigra } \\
\text { demora muchos en } \\
\text { hacerse. }\end{array}$ & $\begin{array}{l}\text { Mujeres artesanas. } \\
\text { Indígenas de } \\
\text { lengua kichwa. } \\
\text { Trabajadoras que } \\
\text { ayudan con sus } \\
\text { artesanías en sus } \\
\text { hogares. }\end{array}$ \\
\hline
\end{tabular}

Fuente: Elaboración propia, en base al proceso de investigación. 
El tercer momento se utilizó para documentar los testimonios de cada una de las participantes junto a su foto-bordado, esto tuvo lugar tres meses después de haber iniciado el proceso etnográfico. En este momento cada una de ellas frente a sus compañeras y a la cámara, expuso el contenido de su tela y de qué manera ese contenido la autorepresentaba.

Si bien el discurso de la mayoría era similar, pues al escuchar a sus compañeras las demás repetían muchos argumentos, se pudo extraer algunos detalles específicos sobre varios asuntos. María Teresa Pala, integrante de la COMANI desde su creación, al igual que la mayoría inicia su presentación con un saludo y agradecimiento, posteriormente realiza un listado de todos los productos artesanales que elaboran en la COMANI, haciendo énfasis en que todas saben hacer de todo. "Este bordadito es para tener recuerdo que yo he trabajado en artesanía", nos cuenta M.

T. Pala (comunicación personal, 30 de junio, 2018) pues para ellas es muy importante que se sepa que son artesanas y que están orgullosas de serlo.

Develando su tela, vemos que sostiene una hoja de cabuya verde a la cual quita sus espinas, y luego de explicar cuál es la diferencia entre la cabuya negra y verde, María Teresa Pala nos relata que en la comunidad hace algunos años atrás, se inició el trabajo artesanal para poder comercializar sus tejidos, pues antes de eso eran sólo de uso personal; sólo tenían ingresos de la agricultura y de los animales que vendían.

Sobre los elementos utilizados en su bordado, explica que son florcitas y adornos puestos en el contorno de la foto, porque a ella le gustan mucho las flores, pero sobre una flor ubicada al interior de la foto nos dijo: "Esta florcita es para que tengan mis hijos de recuerdo, yo la puse por el día de la mamá. Esta foto es de mí... cuando yo muera van a mandar en cajita" (M. T. Pala,comunicación personal, 30 de junio, 2018).

También nos explicó que a ella le gusta bordar de todo, especialmente mangas y cuellos de camisa, pues la identidad en la comunidad de Nizag, como se lo descubriría en el desarrollo de la investigación, tiene en su vestimenta un componente importante, pues a diferencia de las comunidades aledañas, su pollera por ejemplo, marca una distinción en forma, tamaño y materiales con que se realiza el bordado de estas; de hecho son elaboradas exclusivamente en la misma comunidad, determinando una identidad fácilmente reconocible en cualquier espacio y lugar como si de un documento personal se tratase.

Otro de los testimonios considerado para el análisis, es el de María Presentación Vacacela, integrante de la COMANI; ella realiza una descripción primeramente de la fotografía haciendo hincapié en que le gusta este retrato porque le muestra a ella cosechando cabuya y se siente feliz de ser artesana de esta fibra. "Yo bordé siguiendo el filo de las hojas de cabuya y los espinos, también rellené las zonas de las hojas cortadas" (M. P. Vacacela, comunicación personal, 30 de junio, 2018).

Resaltamos que esta forma de trabajar su foto es completamente diferente a todos los demás fotobordados documentados; el dibujar los elementos que constituyen la imagen propiamente dicha, el rellenar algunas zonas como su suéter o los espacios dejados por las hojas cortadas, nos proporciona una reflexión hacia el interior de la imagen, reflejando la importancia otorgada a la planta, ya sea por proporcionarles la fibra con que elaboran sus shigras, o la obtención de una bebida ancestral llamada tzawar mishki o dulce del chahuarquero en español.

Su intención fue intervenir con bordado toda la imagen, pero por sus ocupaciones le resultó muy difícil; sin embargo, espera terminar su trabajo para poder ponerlo en un cuadrito (M. P. Vacacela, comunicación personal, 30 de junio, 2018), para que cuando sea mayor vean sus hijos y nietos $\mathrm{y}$ aún muerta sepan que su madre fue una artesana. "El tejido materializa una narración con el fin de que se convierta en un elemento comunicativo y pueda perdurar durante 
muchas generaciones" (Nates 2017:34). María Natividad Tenemaza, además de repasar nuevamente todos los productos que elaboran en la COMANI, intenta explicarnos cada uno de los siete elementos bordados en su tela. Su nombre lo había bordado en el centro de la parte inferior a manera de título, para lo cual utilizó un color distinto en cada letra de María.

Dos elementos que llaman la atención son una casa y un barco, figuras con características muy básicas, pero que representan dos cosas muy importantes para ella; la primera es su preocupación por no poder terminar la construcción de su vivienda, por lo que el dibujo de una casa sin paredes fue la representación utilizada. Sobre la imagen del barco con vela cuyos colores hacen alusión a la bandera de Ecuador, manifiesta: "Mi hija se fue de migrante en barco, por eso pongo esto, esta tela es un recuerdo para mi" (M. $\mathrm{N}$. Tenemaza, comunicación personal, 30 de junio, 2018).

Prácticamente, en una comunidad en la que todos están emparentados, el tema de la migración es un diálogo cotidiano. Natividad nos cuenta sobre su otro hijo que regresó el año anterior desde los Estados Unidos, "El ya vino a quedarse, pero lamentablemente falleció a los pocos días en un accidente de tránsito con su auto recién comprado; acá muy cerca de la comunidad, en el sector denominado Las Cruces" (M. N. Tenemaza, comunicación personal, 30 de junio, 2018). Al poner el barco en su fotografía bordada, Natividad intenta superar la pérdida de su hijo con una imagen que hace mención a su hija viva y aunque le preocupa su condición de migrante, prefiere recordarla positivamente. Mónica Mendoza, una de las mujeres más jóvenes de la COMANI, inicia su diálogo explicándonos que la comunidad de Nizag se encuentra entre las montañas, por esa razón ella había puesto unos dibujos que hacen referencia a ello. Recordemos que el cantón Alausí y sus comunidades, se hallan en el centro de la Región Interandina o Sierra Central del Ecuador, entre el nudo del Tiocajas al norte y el nudo del Azuay al sur, y a la que en el 2004, el arqueólogo e investigador Jaime Idrovo denominará Bioregión Chanchán.

Uno de los elementos que le interesó destacar de su bordado fue un pequeño ramo de flores multicolores que para ella representan a sus familiares, tanto los que habitan en la comunidad como los que están en el exterior. De igual manera, una rosa lila con capullos rojos y dos hojas bordadas sobre su falda, representan a su esposo quien también migró a Estados Unidos. "Esta flor significa que es mi esposo que está muy lejos y le extraño mucho" (M. M. Mendoza, comunicación personal, 30 de junio, 2018).

Señalando una pequeña flor, explica que representa a sus hijos Jhasú y Erick cuyos nombres también están bordados en la parte inferior de la tela. "Antiguamente han sabido poner anaco por eso hice vestir a mi madre de color negro" (M. M. Mendoza, comunicación personal, 30 de junio, 2018). Además, había dibujado un pequeño árbol que dijo representar al que está sembrado en casa de sus padres y que es muy antiguo, por lo que respetando su pasado no lo piensan tumbar.

Interesada en su cultura, Mónica decidió vestir a su madre con un anaco bordado; fue muy interesante ver lo que pretendía hacer, pues ella nunca vio a su madre con anaco, así que la intervino en su fotografía donde su madre aparece sentada junto a ella en labor de hilado. Al plasmar este elemento cuyo uso en Nizag actualmente se restringe a 12 o 15 mujeres mayores de edad, hay un intento de fijar el recuerdo cultural de su existencia, de proporcionar un tema de diálogo cuando sus hijos le pregunten ¿qué es eso?, y unrespeto hacia su madre, su cultura y tradición; pues como lo diría María Nates "relatar, es un proceso de ilación en el cual se le da sentido a los sucesos de una comunidad, de modo que se transmiten eventos pasados y se construye una colectividad" (Nates 2017:34).

Por su parte Katalina Tapay, prefirió bordar alrededor de la imagen y fuera de ella, pues señala querer dejar libre su fotografía; al hablar de su diseño ella se centró en 
interpretar los colores que había incluido en su foto-bordado. El verde es parte de la naturaleza y de nuestra vida, señala $M$.

K. Tapay (comunicación personal, 30 de junio, 2018). Asimismo, sobre el color rojo manifiesta que siempre lo utiliza en sus tejidos, además de vestirlo en su bayeta. "Me gusta combinar los colores con los de mi vestimenta" (M. P. Tapay, comunicación personal, 30 de junio, 2018). De igual manera, explica que la puntada utilizada se llama zigzag y se usa en los bordados de su atuendo.

Si bien son pocos los datos que nos pudo proporcionar Katalina a través de su fotobordado, consideramos que lo que permitió el ejercicio además de los datos etnográficos, es la oportunidad de abrir el diálogo hacia otros temas fuera del área de bordado, como fue el caso con Katalina, ella aprovechó el momento para hablar sobre su esposo que está en el extranjero y su disgusto por haber participado en un video donde ella aparece caminando hacia la Nariz del Diablo hablando sobre la comunidad y el proceso de elaboración de las shigras. Al parecer le molestó que ella sepa expresarse bien y que no le hayan comunicado primeramente a él antes de subir el video a YouTube.

Según se observó, este aspecto de control a la distancia por parte de los esposos especialmente hacia sus esposas, es bastante común en la comunidad. A Katalina le molestaba que le prohíba tomar sus propias decisiones con respecto a asuntos personales como el estudio, el trabajo en la COMANI o simplemente lo que debe o no hacer.

Este asunto llevó instintivamente a Katalina a decorar su retrato externamente sin la pretensión de contar una historia per se, sino liberarla de cualquier intervención o atadura, embelleciéndola con alegorías y colores propios de su cultura. Según Ximena Triquell, la imagen "posee un grado de ambigüedad mayor que el lenguaje escrito. En esta ambigüedad funda posibilidades interpretativas diversas..." (2012:162).

Katalina también comentó que estaba muy arrepentida tanto de no tener tiempo para asistir al taller artesanal a trabajar junto a sus compañeras, así como de no haber podido cosechar las flores y plantas necesarias para teñir las fibras de cabuya, pues considera que deberían volver a la forma ancestral de elaboración de colores para confeccionar sus artesanías, ya que actualmente la mayoría utiliza tintes artificiales para teñir.

Cabe mencionar que a pesar de que todas las participantes en este ejercicio de fotobordado, pertenecen a la comunidad y tejen shigras ya sea para su uso personal o para su venta, ninguna utilizó elementos que se incluyen en el diseño de esta prenda ancestral; es decir, a pesar de contar con una amplia simbología aprendida desde que son pequeñas, no incluyeron esos elementos es sus bordados; si bien es cierto que se trataba de un ejercicio distinto a lo habitual, también es cierto que nunca se les dijo que no deben usarlos. Solo puedo reflexionar por lo observado y los datos obtenidos, que la shigra para ellas es una expresión fundamental de su cultura e identidad indígena, no así el foto-bordado que fue algo externo y experimental, ajeno a su tradición. Sobre la autorepresentación evidenciada en los fotobordados, podemos mencionar que una constante en los discursos tanto verbales como visuales, tiene que ver con su auto identificación como artesanas, mujeres orgullosas de su oficio, capaces de poder ayudar a la economía del hogar. También la condición de mujer, madre, esposa, hija e indígena fue registrada firmemente.

Temas como la migración, a pesar de lo polémico y emocional de su realidad, se destaca entre los argumentos, así como la familia, su tradición textil, sus conocimientos agrícolas, sus animales y la ubicación privilegiada de su comunidad. Aunque hubo mucha similitud entre los elementos utilizados en los diseños, fueron en sus discursos personales donde se distinguían y autorepresentaban únicas.

Terminada esta breve revisión de datos, sin duda que como gestor y observador de la etnografía experimental planteada, la expectativa personal era alta sobre los 
datos que pudiera aportar el ejercicio sobre el conocimiento cultural e identitario de las tejedoras, así como de sus discursos socioculturales que se desprendan de ellos; sin embargo, consideramos escasos los datos obtenidos aunque no por ello menos importantes.

Ahora bien, de las 23 participantes del ejercicio etnográfico, sólo se incluyen cinco testimonios de los 16 retratos que se expusieron frente a la comunidad (figura 2), estos fueron escogidos por los contenidos del discurso y porque algunas tejedoras repetían muchos detalles ya expuestos por sus compañeras, no aportando nada nuevo a los diálogos ya registrados; es decir, sólo el testimonio del $22 \%$ de las mujeres participantes, por lo que una revisión a la metodología utilizada se hace necesaria tomando en cuenta que el tiempo destinado al ejercicio fue más que suficiente para lograr obtener información relevante por otro medio.

Otros datos obtenidos nos cuentan que de las 23 tejedoras, 16 expusieron su trabajo terminado; dos los tenían aún en proceso; tres habían enviado sus trabajos a sus familiares en el extranjero sin que se pudiera previamente registrarlos; y dos nunca los presentaron.

Sobre los materiales utilizados se destacan principalmente los hilos de orlón en una amplia gama de colores y las lentejuelas. Sobre la manera en que sus retratos fueron intervenidos, sobresalen una representación interior, sobre la imagen impresa, y otra exterior sin tocar la imagen, lo que nos permite pensar no sólo en términos estéticos, sino además que una intervención sobre la imagen, nos habla de pretender completar el retrato con elementos que le falta, pues mientras más elementos incorporaban, su posibilidad de crear una narrativa gráfica era mayor. Por lo contrario, una intervención externa era más estética, su interés era enmarcar su retrato, a quien representa, y que nada la ensucie o distraiga, donde el discurso era más externo al bordado, el cual se construía con su retrato no con los elementos incorporados.

Sobre los elementos incluidos en el diseño de sus fotobordados sobresalen las flores y hojas, corazones, estrellas, adornos de todo tipo y forma, sus nombres o de algún

Fuente: Elaboración propia

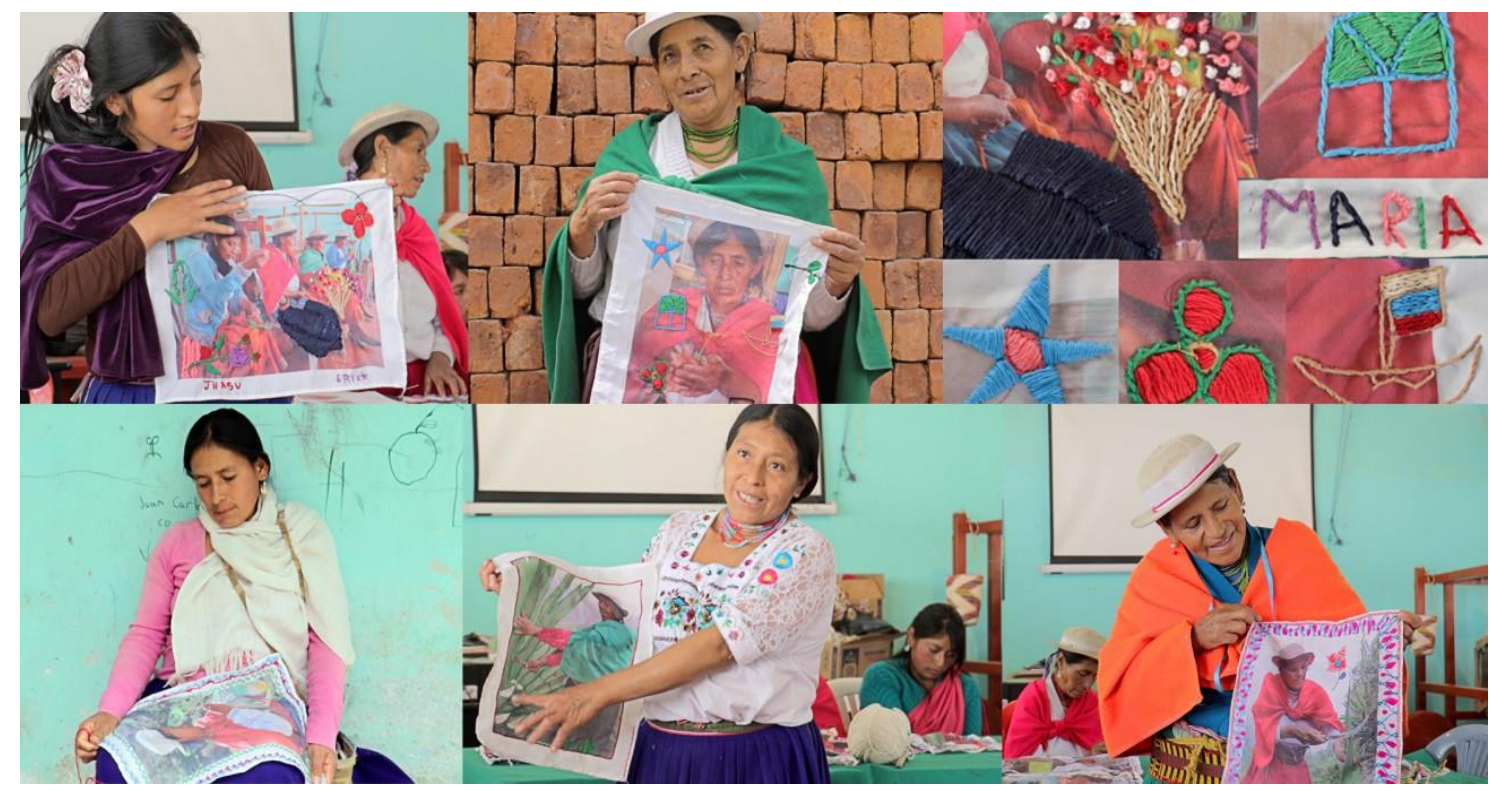

Figura 2: Trabajos de foto-bordado y detalles. 
familiar, nombre de lugares, e intervención directa en la imagen. En resumen, los elementos utilizados en el ejercicio de autorepresentación, se los puede observaren y desde su comunidad, forman parte de sus emociones, preocupaciones y deseos.

Creemos importante que la metodología debe estar acorde a las posibilidades técnicas, manuales y prácticas de las participantes, así como de disposición de tiempo y compromiso con la actividad. Luego de analizar algunos pasos dados para la ejecución de este ejercicio de fotobordado, hemos comprendido que no se puede esperar tener resultados similares a los logrados por otros investigadores en trabajos parecidos con grupos de mujeres artesanas, tanto urbanas como rurales, pero con otras realidades, necesidades y posibilidades, donde los talleres de trabajo para la ejecución del ejercicio fueron fundamentales.

La realidad con la que nos encontramos en la comunidad era diferente $\mathrm{y}$ a pesar de reunirse una vez a la semana a trabajar en su taller artesanal, no era propiamente para realizar su foto-bordado, sino para discutir asuntos relacionados a la organización, a la comunidad y principalmente a tejer sus shigras. Advertimos que el ejercicio defotobordado fue tomado como un trabajo extra a sus actividades, fue visto más como una tarea externa, impuesta, no necesaria o que les vaya a rendir réditos económicos, pues entendemos que su trabajo artesanal, la agricultura, la comunidad o el hogar, para ellas sea lo primero.

Creemos que un taller previo para aprender a pasar imágenes desde impresiones caseras hubiese sido fundamental para que ellas se apropien del trabajo de bordado que luego se realizaría. Aprender a llevar las imágenes impresas en papel a la tela de manera artesanal, sería primordial, pues eso les permitiría no solo usar una imagen para su autorepresentación, sino tener varias opciones y en tamaños diferentes; dominada la técnica incluso se podría pensar como un nuevo producto de comercialización.

En la exposición de los fotobordados frente a la comunidad de Nizag (figura 3), si bien todas dijeron estar muy orgullosas y felices de poder mostrar lo realizado, aquel día, ya sea porque el acto inició tres horas tarde o porque se impuso el orden y

Fuente: Fotografía tomada por Mónica Cajo.

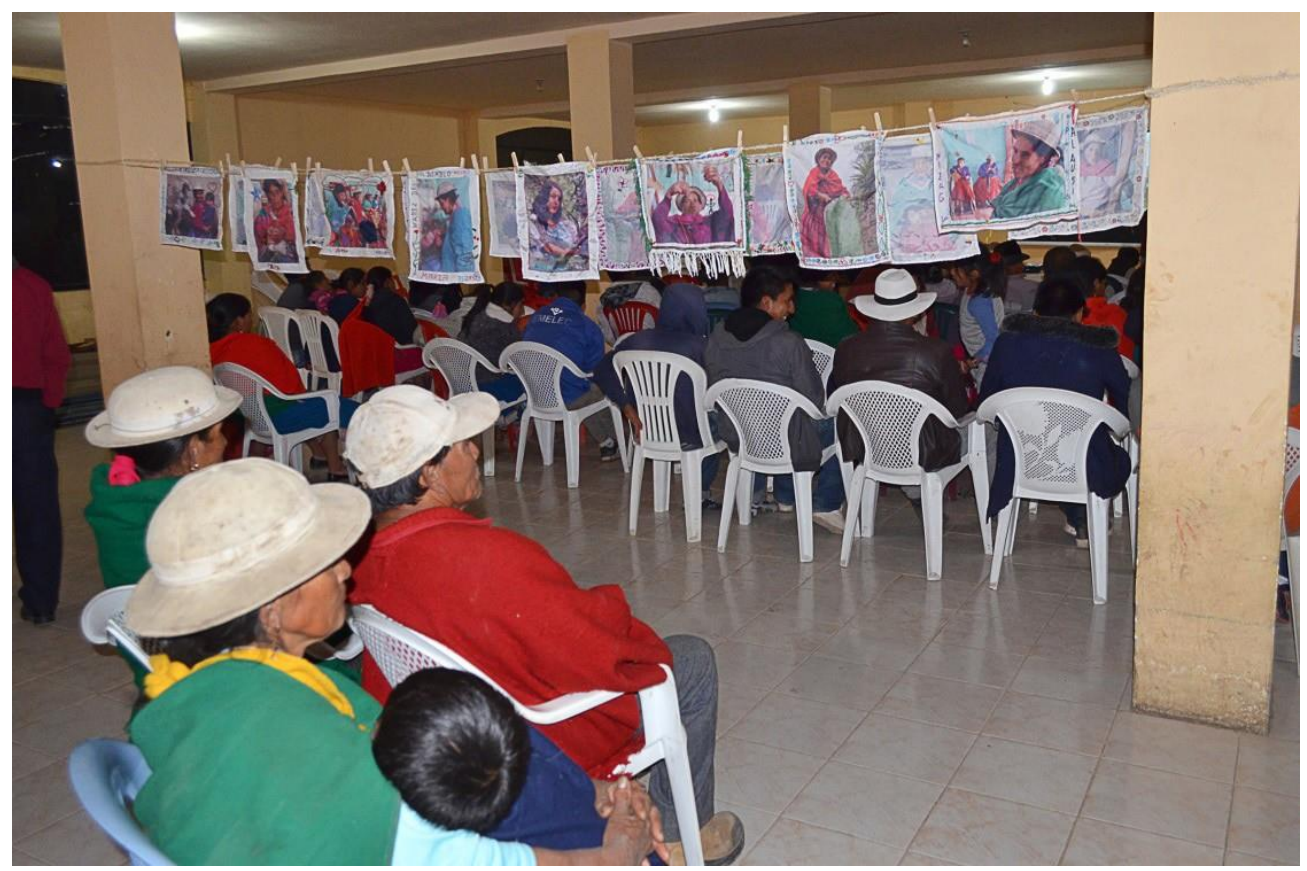

Figura 3: Exposición de fotobordados en la casa comunal de Nizag.

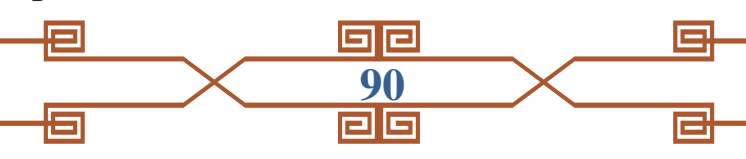


programa propuesto por las autoridades de la comunidad, no hubo tiempo para que las mujeres puedan expresar frente a sus telas el trabajo de autorepresentación realizado; pero lo que sí se escuchó fueron opiniones de algunos asistentes no residentes de la comunidad, sobre lo hermoso de los trabajos a los que calificaron de arte; sobre la importancia concedida a las mujeres y la comunidad; y sobre el rescate de técnicas de bordado.

Luego de describir y analizar los resultados, reflexionamos que la autorepresentación de las mujeres tejedoras de Nizag a través del foto-bordado, sí generan discursos socioculturales en la etnografía experimental, pues a pesar de los escasos datos obtenidos, y la necesidad de una revisión a la metodología implementada, los discursos generados a partir de su autorepresentación, nos proporcionan referencias y conocimiento significativo para comprender al otro en su entorno social, cultural, político y económico.

\section{CONCLUSIONES}

La implementación de una etnografía experimentalatravés de laautorepresentación por medio del fotobordado, ha permitido identificar algunos detalles sobre las tejedoras que se desconocían, comprender aspectos de la dinámica entre migrantes y habitantes de la comunidad, sus relaciones sociales, la importancia otorgada a su labor de tejido y lo complicado que les resulta cumplir con un programa de actividades que estén fuera de su cotidianidad o necesidad. Las autorepresentaciones evidenciadas en los fotobordados, las ratifican como mujeres indígenas, artesanas, herederas de saberes ancestrales, protectoras de su cultura e identidad comunitaria, así como preocupadas de los problemas sociales que la migración ha traído a sus vidas, pero convencidas que la familia es importante como unidad cuyos lazos deben fortalecerse. También destacan las posibilidades agrícolas de la comunidad, su entorno y ubicación.

Auto identificarse como mujer indígena perteneciente a la COMANI, constituye motivo de orgullo y responsabilidad, al ser quienes trasmiten ese conocimiento a las nuevas generaciones, como un acto de resistencia al actual distanciamiento de la tradición comunitaria por parte de los jóvenes.

Es importante señalar que la aplicación de esta etnografía experimental, a pesar de sus posibles falencias, generó conocimiento en la lectura personal de los fotobordados, evidenciando en sus autorepresentaciones, sus preocupaciones, deseos, sentimientos, resistencia y su cultura; además de que aportó datos precisos para la investigación, que servirán para implementaciones futuras.

\section{REFERENCIAS BIBLIOGRÁFICAS}

Ardévol, E. (1998). Por una antropología de la mirada: etnografía, representación y construcción de datos audiovisuales. Revista de dialectología y tradiciones populares, 53(2), 217-240.

Auqui, F. (2016). Microverticalidad, poder y mercado en los Andes Equinocciales. (Master's Thesis), FLACSO Sede Ecuador, Quito, Ecuador.

Collette, A. (1969). Introducción a la Psicología Dinámica de las Teorías Psicoanalíticas a la Psicología Moderna. Buenos Aires: Losada S. A.

Gratton, B. (2005). Ecuador en la historia de la migración internacional ¿Modelo o aberración? En La migración ecuatoriana Transnacionalismo, redes e identidades (FLACSO, Sede Ecuador; Plan Migración, Comunicación y Desarrollo). Quito.

Idrovo, J. (2004). Aproximaciones a la historia antigua de la Bio-Regióndel Chanchán (Municipal de San Pedro 
de Alausí). Quito, Ecuador: América Latina.

INEC. (2002). Migración y Distribución Espacial 1990-2001. Quito: Instituto Nacional de Estadística y Censos.

INEC. (2010). Pobreza por necesidades básicas insatisfechas. Recuperado de http://www.ecuadorencifras.gob. ec/pobreza-por-necesidades-basicasinsatisfechas/

Mancero, D. (2001). La crisis bancaria ecuatorIana. Revista del Centro Andino de Estudios Internacionales, 1, 125-131.

Marcus, G. E. \& Fischer, M. M. J. (2000). La antropología como crítica cultural: un momento experimental en las ciencias humanas. Buenos Aires: Amorrortu.

Martínez, M. G. (septiembre de 2013). Subjetividad y lenguaje: aportes al estudio de discursos socioculturales. En $X$ Congreso Argentino y $V$ Latinoamericano de Educación Física y Ciencias. Congreso llevado a cabo en La Plata, Argentina. Recuperado de http://hdl.handle. net/10915/39109

Nates, M. E. (2017). Narrar con hilos: la memoria y la narrativa como herramientas de sanación a través del tejido (Tesis de grado). Pontificia Universidad Javeriana.

Rivera, M. (2012). Sueños de mayo: la etnoficción como metodología para entender elfenómeno onírico entre los tiemperos de San Pedro Nexapa en el estado de México. (Tesis de Maestría, Flacso Ecuador). Recuperado de http://repositorio.flacsoandes.edu.ec/ handle/10469/5665

Salomon, F. (1980). Los señoríos étnicos de Quito en la época de los Incas. (Vol. 10). Otavalo, Ecuador: Instituto Otavaleño de Antropología.

Triquell, X. (2012). Fuera de cuadro: Discursos audiovisuales desde los márgenes. Eduvim.

Zirión Pérez, A. (2015). Miradas cómplices: cine etnográfico, estrategias colaborativas y antropología visual aplicada. Iztapalapa, Revista de Ciencias Sociales y Humanidades, (78), 45-70. 